\title{
Diffuse hypertrophy of gastric mucosa (Menétrier's disease) and iron-deficiency anaemia
}

\author{
A. K. SINGH, R. C. CUMARASWAMY, AND B. CORRIN \\ From St Thomas' Hospital and Medical School, London
}

SUMMARY A 23-year-old woman presented with intractable iron-deficiency anaemia. A barium meal showed widespread mucosal abnormalities in the stomach and massive mucosal hypertrophy was found at laparotomy. Repeated tests for occult blood were negative but gastrointestinal haemorrhage was confirmed by isotopic blood labelling. In the face of persistent anaemia and radiological progression, total gastrectomy was performed, since when a normal blood picture has been maintained. The excised stomach showed hyperplasia of all the mucosal elements, minimal inflammation, and no obvious bleeding point. Blood loss was attributed to diapedesis from a greatly increased capillary network.

Diffuse hypertrophy of gastric mucosa, first reported by Menétrier (1888), and sometimes called Menétrier's disease, has been variously described as giant hypertrophic gastritis, gastric polyposis, tumoral gastritis, or cystic and follicular gastritis. It is a rare disease and Butz (1960) observed that the number of authentic cases recorded was probably less than 100 . The symptoms usually resemble ulcer dyspepsia, and hypoproteinaemia due to loss of serum protein into the gastric lumen is frequently present. Haematemesis or melaena occasionally occurs (Bockus, 1963; Jones, Gummer, and Lennard-Jones, 1968) but chronic blood loss has not been reported previously. The present paper describes a patient in whom recurrent iron-deficiency anaemia due to chronic blood loss was the sole manifestation and illustrates some unusual aspects of the disease.

\section{CASE-REPORT}

L.H., a woman aged 23 years, was treated for irondeficiency anaemia with Jectofer and ferrous sulphate in January 1967. An initial improvement was not maintained and the patient was referred to St Thomas' Hospital in June 1967 for further investigations. The initial findings and subsequent course are shown in Figure 1. At this time the haematological findings were: haemoglobin 5.3 g; MCHC 22\%; reticulocytes, $22 \%$; WBC, $4,200 / \mathrm{cmm}$ (normal differential count); platelets, $145,000 / \mathrm{cmm}$; a peripheral blood film showed marked anisocytosis and hypochromia; serum iron, $115 \mu \mathrm{g} \%$ and unsaturated iron-binding capacity, $650 \mu \mathrm{g} \%$. A bone marrow aspiration biopsy showed normal erythropoiesis
Ferrous Sulphate $200 \mathrm{mg}$ t.d.s.
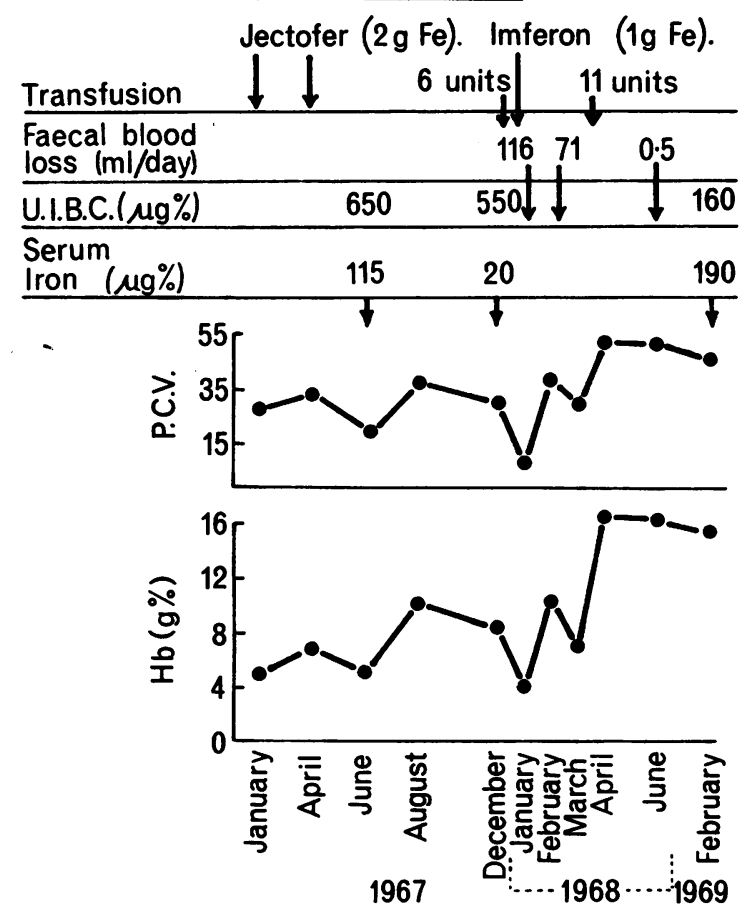

FIG. 1. Summary of haematological findings and treatment. 


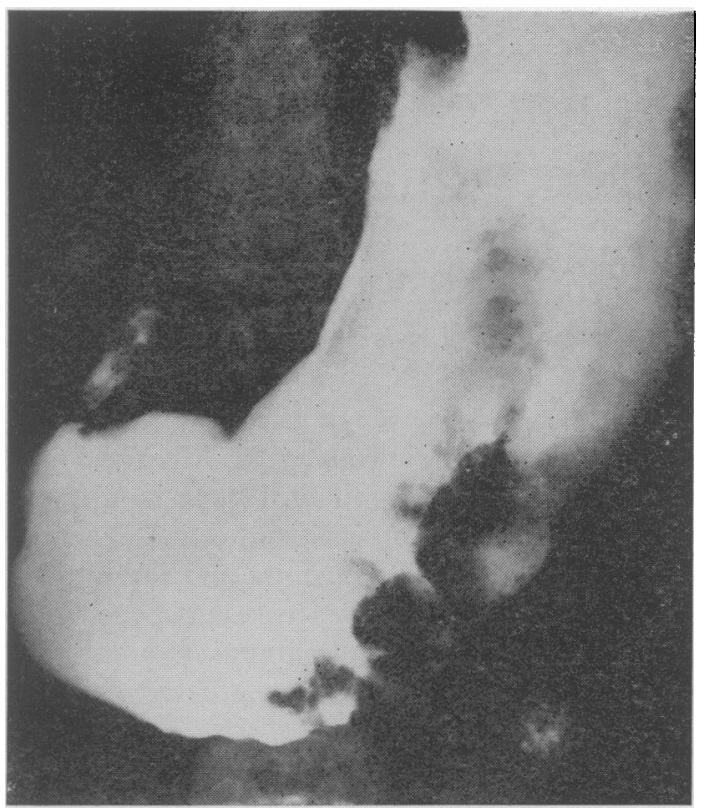

FIG. 2. Large filling defects and absence of normal mucosal pattern in the stomach shown by barium meal.

and granulopoiesis but complete absence of stainable iron in the marrow fragments. On the basis of these findings. the diagnosis of iron-deficiency anaemia was confirmed. Plasma proteins, liver function tests, faecal fat $(7 \cdot 6 \mathrm{~g} /$ day $)$, and jejunal biopsy appearances were all normal. Repeated tests for occult blood (Hematest) in faeces were negative and the menstrual blood loss was judged normal. She was therefore treated with Jectofer again and a few days later the reticulocyte count rose to $9.4 \%$ and two months later the haemoglobin level had risen to $11 \cdot 2 \mathrm{~g} \%$. Thus, by this time the diagnosis of iron-deficiency anaemia was firmly established but no cause had been found.

When seen in December 1967 anaemia had again recurred although administration of oral iron had been continued during the interval. The haematological findings were: haemoglobin $8.6 \mathrm{~g} \%$; PCV $30 \%$; MCHC $29 \%$; and ESR $11 \mathrm{~mm}$ in one hour. A peripheral blood film showed a mixed population of normochromic and hypochromic cells; serum iron $20 \mu \mathrm{g} \%$ and unsaturated iron-binding capacity $550 \mu \mathrm{g} \%$. Plasma protein and liver function tests were normal. Repeated tests for occult blood loss in faeces (Hematest) were again negative. A barium meal showed the absence of the normal mucosal pattern and large filling defects throughout the body of the stomach extending as far as the fundus (Fig. 2). The oesophagus and the duodenal cap were normal. On the basis of these findings a provisional diagnosis of an extensive infiltrating neoplasm of the stomach was made. She was then transfused with 6 units of whole blood as packed cells, and a laparotomy was performed in January 1968. At operation the stomach showed massive mucosal hypertrophy with large folds and a cobblestone appearance of the surface. No ulcers were seen. A frozen section of a full-thickness biopsy from the fundus and a strip of mucosa from the antrum showed no evidence of neoplasia and no further surgery was undertaken. During the postoperative period the patient was given $1 \mathrm{~g}$ of iron as a total dose infusion in saline and discharged six weeks later when the haemoglobin level had risen to $11 \cdot 3 \mathrm{~g} \%$.

The suspected gastrointestinal blood loss was eventually confirmed and measured using the patient's own red cells labelled with radioactive sodium chromium $\left({ }^{51} \mathrm{Cr}\right)$. Over a period of six days blood loss ranged from 21 to $159 \mathrm{ml}$ per day $($ mean $=116 \mathrm{ml} /$ day). A repeat

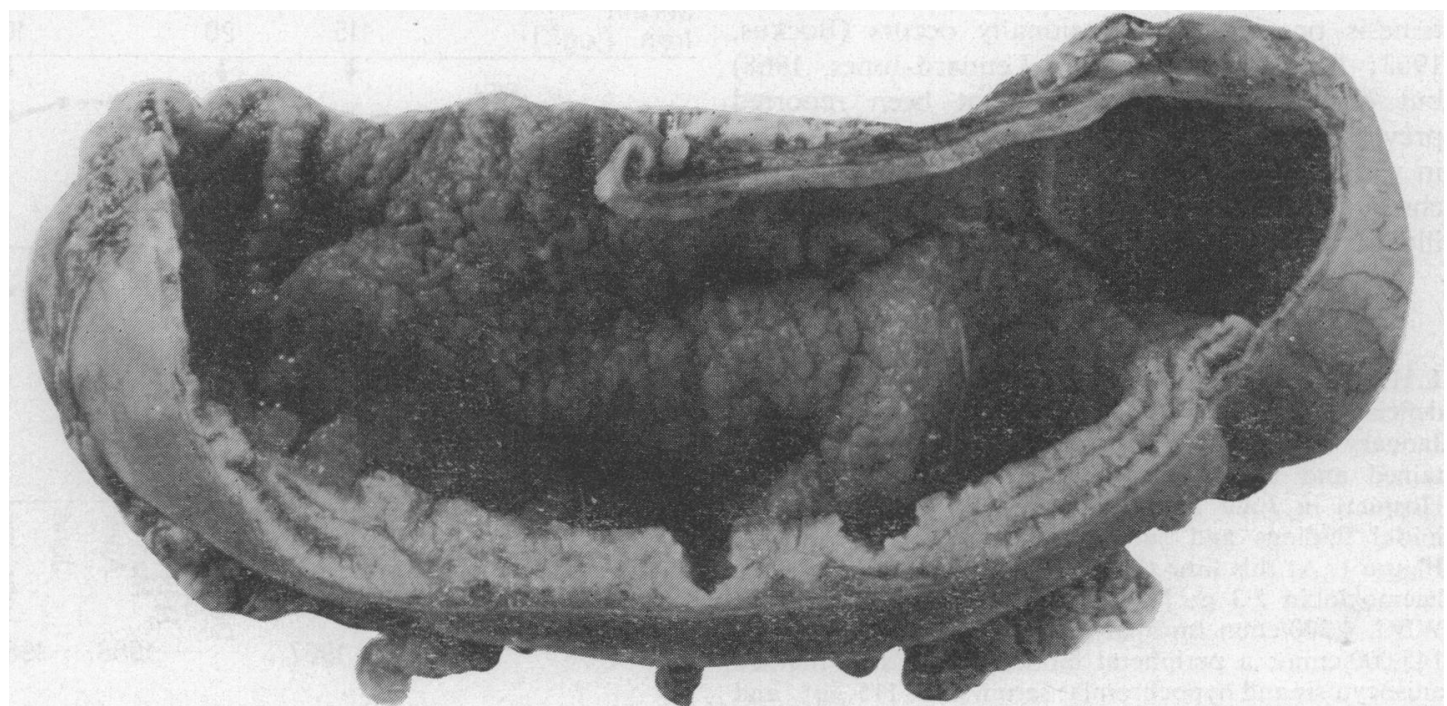

FIG. 3. Naked-eye appearance of the interior of the stomach showing thickening of the mucosa. These changes were present in the body and the fundus but the antrum was normal. 
barium meal suggested that the changes in the stomach had progressed. Smal! bowel meal and barium enema revealed no abnormality. Proctoscopic and sigmoidoscopic examinations were normal. An attempt was made to localize the site of bleeding by continuous aspiration of the stomach and upper small intestine after a further injection of ${ }^{51} \mathrm{Cr}$-labelled cells, but no radioactivity was detected in the 48-hour aspirate. Over the next five days the faecal blood loss continued, varying from 11 to $85 \mathrm{ml}$ per day $($ mean $=71 \mathrm{ml} /$ day), and total gastrectomy was consequently decided upon. Three months after the operation the gastrointestinal blood loss was measured again, and varied from 0.3 to $0.9 \mathrm{ml}$ per day (mean $=0.5 \mathrm{ml}$ / day) when it became clear that the recurrent irondeficiency anaemia had resulted from pronounced blood loss from the stomach and that this had ceased after gastrectomy. At the same time menstrual blood loss was measured during one period by collecting soiled pads and comparing their radioactivity with that in the whole blood. It amounted to $6.8 \mathrm{ml}$ of whole blood which showed that menstrual loss had made no significant contribution to the iron-deficiency anaemia. Since the operation the patient has maintained normal levels of haemoglobin, serum iron, and unsaturated iron-binding capacity and has not required iron therapy.

PATHOLOGICAL CHANGeS IN THE STOMACH In its fixed condition the stomach measured 16 and $34 \mathrm{~cm}$ along the curvatures. The external surface showed no abnormality, but there was considerable thickening of the wall (Fig. 3). This involved the whole of the corpus and fundus but spared the antrum and was entirely due to mucosal hypertrophy. The mucosa measured up to $1.4 \mathrm{~cm}$ in thickness. Its rugal folds were exaggerated and its surface had a cobblestone appearance.

Microscopy showed that the thickening was due to mucosal hyperplasia. All normal elements including

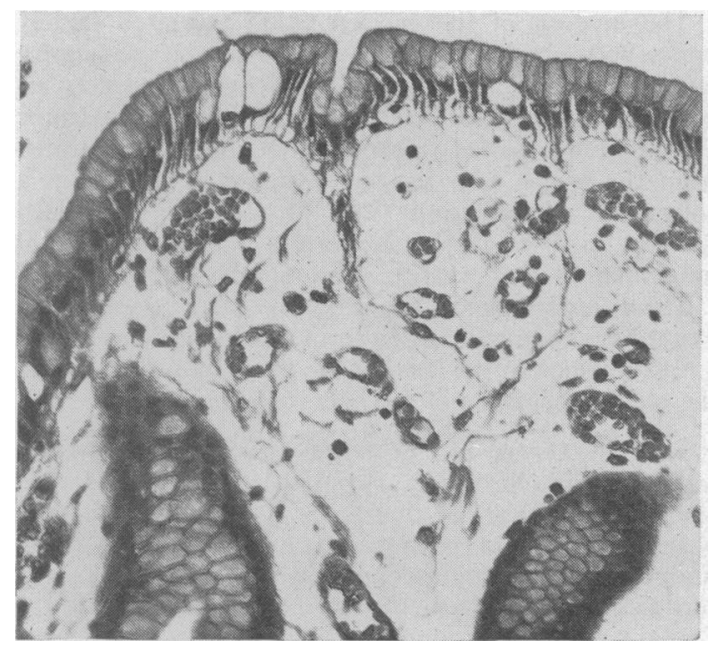

FIG. 4. Histological appearance of the gastric mucosa showing dilated capillaries and diapedesis of red cells. $\times 120$. mucous neck cells, zymogenic, and parietal cells were involved and the normal cell ratios were maintained. The gastric pits and glands were greatly lengthened. The normal fine furrowing of the mucosa was grossly accentuated giving the cobblestone appearance seen by the naked eye. The muscularis mucosae was slightly hypertrophied and in many places drawn up into the mucosa. Deeper glands were sometimes obstructed and showed microcystic dilatation. Inflammatory changes were minimal. The muscle and serosal coats were normal. There was no evidence of ulceration to account for the haemorrhage, but capillary engorgement and diapedesis were prominent immediately beneath the surface epithelium (Fig. 4).

\section{COMMENT}

The case described in this report had none of the usual clinical features of this disease, and the patient presented with recurrent iron-deficiency anaemia due to persistent occult bleeding from the stomach. Although it was not possible to identify the precise site of the blood loss before the operation, complete cessation of bleeding and maintenance of normal haemoglobin levels after gastrectomy conclusively demonstrated that the stomach was the only source of the persistent haemorrhage. There were no ulcers or abrasions in the stomach, but the presence of a vast network of dilated capillaries under a greatly increased epithelial surface was easily recognized. It is likely that blood loss resulted from exudation of red corpuscles from these capillaries.

The diagnosis of giant hypertrophy of the gastric mucosa is often in doubt. The gastroscopic and radiological appearances are indistinguishable from infiltrating carcinoma or lymphoma (Bockus, 1963; Jones et al, 1968) and in this case the diagnosis was only established after the stomach had been removed. Spontaneous regression has been reported (Grime and Whitehead, 1951; Frank and Kern, 1967), but the severity of blood loss in this patient clearly justified total gastrectomy.

We are grateful to Professor W. I. Cranston for allowing us to study this patient who was admitted under his care.

\section{REFERENCES}

Bockus, H. L. (1963). Gastroenterology, Vol. I, Saunders, Philadelphia.

Butz, W. C. (1960). Giant hypertrophic gastritis: a report of 14 cases, Gastroenterology, 39, 183-190.

Frank, B. W., and Kern, F., Jr. (1967). Menétrier's disease. Ibid., 53, 953-960.

Grime, R. T., and Whitehead, R. (1951). Giant hypertrophic gastrit is simulating malignant disease. Brit. J. Surg., 39, 244-246.

Jones, F. A., Gummer, J. W. P., and Lennard-Jones, J. E. (1968). Clinical Gastroenterology, 2nd ed. Blackwell, Oxford.

Menétrier, P. (1888). Des polyadénomes gastriques et de leurs rapports avec le cancer de l'estomac. Arch. Physiol. norm. path., 1, 32-55, 236-262. 